\title{
A Theoretical and Qualitative Approach to Evaluating Children's Robot-Mediated Levels of Presence
}

\author{
Veronica Ahumada-Newhart ${ }^{1,2}$ and Jacquelynne S. Eccles ${ }^{2,3}$ \\ ${ }^{1}$ Institute for Clinical and Translational Science, University of California, Irvine \\ ${ }^{2}$ School of Education, University of California, Irvine \\ ${ }^{3}$ Institute for Positive Psychology and Education, Australian Catholic University
}

\begin{abstract}
Each year, 2.5 million children in the United States are homebound due to illness. This paper explores the possible implications of being homebound for child development and well-being, drawing on Bronfenbrenner's bioecological systems theory of human development and Ryan and Deci's self-determination theory. This paper also explores the potential role of robotic avatars and robotmediated presence to provide homebound children with more appropriate developmental experiences. To better understand their robot-mediated developmental experiences, what is known about human development and human psychology in organic environments (i.e., bioecological systems theory and self-determination theory) is synthesized with concepts of presence theory from virtual environments. These theoretical supports form the foundation of a framework to evaluate the robot-mediated presence of homebound children. Findings from the first systematic, multicase study on the robot-mediated presence of homebound children in schools provide empirical data to inform three identified levels of presence: copresent, cooperating, and collaborating. This framework provides a first step to consistent evaluation of robot-mediated presence and engagement for this population. Understanding the social contexts and developmental needs of homebound children and how they can be achieved via robotic avatars will aid in developing more effective interventions for improved social supports and technological systems.
\end{abstract}

Keywords: human-robot interaction, child development, presence, collaborative robots, augmented reality

Each year, millions of children are homebound due to illness that requires limited exposure to other children and adults due to health risks. What are the consequences of this isolation for their development and well-being, and how might robotic avatars be used to enrich their developmental experiences? These are the questions

Action Editor: Danielle S. McNamara served as the action editor for this article.

ORCID iDs: Veronica Ahumada-Newhart (iD https://orcid.org/00000001-6983-9726; Jacquelynne S. Eccles (D) https://orcid.org/0000-00026405-9330.

Disclosure and Acknowledgments: The authors do not have any real or potential conflict(s) of interest. This work was supported by the National Center for Research Resources and the National Center for Advancing Translational Sciences, National Institutes of Health, through Grants UL1 TR000153 and TL1 TR001415. The content is solely the responsibility of the authors and does not necessarily represent the official views of the NIH. Study data are not publicly available at this time to protect the privacy of participants. Due to small sample size, sharing participants' data could violate confidentiality.

Open Access License: This work is licensed under a Creative Commons Attribution-NonCommercial-NoDerivatives 4.0 International License (CCBY-NC-ND). This license permits copying and redistributing the work in any medium or format for noncommercial use provided the original authors and source are credited and a link to the license is included in attribution. No derivative works are permitted under this license.

Disclaimer: Interactive content is included in the online version of this article.

Contact Information: Correspondence concerning this article should be addressed to Veronica Ahumada-Newhart, Institute for Clinical and Translational Science, UC Irvine, Irvine, CA 92697, United States. Email: vnewhart@uci.edu guiding this paper. Fundamental developmental theories and theories of thriving make clear the importance of exposure to larger social settings for normative healthy human development. This paper draws upon both Bronfenbrenner's bioecological systems theory of human development (Bronfenbrenner, 2005) and Ryan and Deci's self-determination theory (SDT) (Ryan \& Deci, 2000) to justify the importance of exposure to the kinds of experiences children normally receive in school settings for normative development. Theories related to virtual reality are also explored to evaluate the role that social presence, through robotic avatars, plays in providing homebound children with developmental experiences. This paper introduces the first systematic, multicase study on the robot-mediated presence of homebound children in traditional schools. Findings include empirical data that inform a theoretically supported framework for evaluating the robot-mediated presence of children in learning environments.

\section{Literature Review}

\section{Medically Homebound Children}

Understanding the population of homebound children and their social contexts of engagement not only provides insight into how children interact socially in schools via these robots but also aids in developing more effective robotic systems for this population. There are a number of serious medical conditions that keep children from physically attending school (e.g., childhood cancer, chronic immune deficiency, heart disease, sickle cell disease, and HIV/AIDS). These and other medical conditions may make a child especially vulnerable to diseases that are commonly passed among children at school. With advancements in medicine that result in 
improved survival rates for these conditions, comes greater need for advancements in technology to ensure the quality of life for children living with serious medical conditions. Telepresence robots are a promising technology to address the needs of homebound children. However, child-centered studies that holistically evaluate the effects of this robot use are needed.

A foundational block of any, if not all, child-robot interaction work is a strong understanding of traditional childhood social and developmental experiences. Most homebound children in this study are traditional learners until symptoms, diagnosis, or treatments of a medical condition require them to be homebound. Homebound children are physically segregated from school and other social settings for extended periods of time due to associated health risks. Although some homebound children experience physical challenges, many do not have an increase in cognitive challenges that prevent them from participating in social and academic activities (Ahumada-Newhart \& Olson, 2019; Newhart et al., 2016; Newhart \& Olson, 2017).

For most homebound children, the need for equal access to the same learning outcomes, both academic and social, remains the same as that of their healthy peers. However, current homebound educational services do not provide children with the social and academic experiences necessary for positive long-term social or cognitive outcomes. In the United States, homebound children receive minimal home instruction services (typically 4-5 hr/week) (Disability Rights California, 2012; Newhart \& Olson, 2017) even though research has shown that inclusive educational practices result in better social and academic outcomes for all children (Gurney et al., 2009; Maslow et al., 2011). Being removed from school and losing contact with peers for significant periods of time likely undermine both healthy social and cognitive development, as well as create anxiety and fears about disrupted friendships and concerns about falling behind academically (Charlton et al., 1986; Sullivan et al., 2001).

\section{Size of the Homebound Population}

To gauge the size of this population with recent data, figures from the 2016 U.S. Census (U.S. Census Bureau, 2016) and the 2016 National Health Interview Survey (NHIS, 2016) were reviewed. U.S. Census figures estimate the total 2016 U.S. population between ages 5 and 17 (i.e., school aged) to be about 53,739,000. NHIS (2016) estimates that, during the academic year, $4.2 \%$ of children in this age group (i.e., 5-17 years) missed 11 or more days of school, and $0.5 \%$ did not attend school at all due to illness. Based on NHIS estimates, the number of school-aged children in 2016 who missed significant amounts of school (i.e., 11+ days of school) due to illness would be 2,257,000, and the number who did not attend school at all due to illness would be 269,000 . Through detailed evaluation of both U.S. Census data and NHIS data, the size of the U.S. child population who are significantly homebound is estimated at a more conservative figure of $4.7 \%$, or $2,526,000$ out of $53,739,000$ school-aged children in the United States. The population of children who are not able to physically attend school due to medical conditions is significant at an estimated 2.5 million. This population is expected to grow as survival rates improve for many illnesses. This growing population of children is well enough to leave the hospital but not well enough to physically attend school or social activities.

\section{Cognitive and Socioemotional Benefits of Telepresence Robot Use}

Very little research has been conducted on the use of telepresence robots by homebound children for daily social and academic experiences (Ahumada-Newhart \& Olson, 2019; Newhart et al., 2016, 2017; Newhart \& Olson, 2017). Prior research explored the cognitive and socioemotional benefits of this emerging practice (Newhart et al., 2016). In this research, three themes emerged from the coding and analysis of the data: (a) anthropomorphism for social acceptance and normalcy, (b) overcoming isolation to meet socioemotional needs, and (c) new experiences that generated talk of an academic and social future. In addition, this research identified Ryan and Deci's SDT as a key theoretical support for future work (Ryan \& Deci, 2000). SDT posits that all humans have universal, innate psychological needs (i.e., competence, autonomy, and relatedness) and that people develop and function optimally only when these needs are met. More specifically, in order for humans to actualize their inherent potential, their social environments must nurture these needs. Being homebound, by its very nature, fails to meet these needs because it socially isolates children from the types of enriched social environments needed both to fulfill children's needs for competence, relatedness, and autonomy and to develop the social skills necessary to meet these needs when they return to school.

Earlier studies found that using telepresence robots to interact in their school's social environment allowed students to feel capable of using a robot to interact successfully with classmates, teachers, and other school personnel. This capability reinforced the students' developing feelings of autonomy, relatedness, and competence (Newhart et al., 2016). In this study, all participants claimed to feel included in class; classmates referred to the robot by the homebound child's name as opposed to calling it a device or a robot. In addition, parents noted significant increases in their children's interest and happiness at being with their friends. However, as the sample size for this study was quite small, it is unclear how these benefits varied by age, gender, school setting, or duration of hospital/homebound experience.

\section{Virtual Inclusion}

In this paper, the term "virtual inclusion" refers to educational practices that allow homebound children to attend school through the use of robotic telepresence in such a way that they are able to interact with classmates, teachers, and other school personnel as if they were physically present (Newhart et al., 2016). Virtual inclusion is the user's compelling sense of being in a technology-mediated space (e.g., the classroom) and not where the physical body is located (e.g., the home) much like virtual reality where a remote person feels present in a virtual environment (Kim \& Biocca, 1997; Minsky, 1980). Ideally, homebound children can feel as if they are in attendance at school and engaged in educational experiences along with peers. If so, then virtual inclusion via telepresence robots may provide the opportunity for the children to maintain social connectedness and relationships with their peers, teachers, and administrators through computer- and robot-mediated communications. The robots may allow children not only to participate visually and verbally in their 
classes but also to experience dynamic interactions within the classroom and school. Mobile telepresence robots have an added physical presence that is missing in other communication devices, which, combined with movement, enhances the perception of a social link for the operator (Nakanishi et al., 2009).

\section{Commercially Available Telepresence Robots}

For effective child-centered studies, it is critical to understand the uniqueness of the homebound child's experience. The telepresence robot is an innovative technology that can remove the barrier of physical segregation. However, an embodied robot can provide levels of presence that vary from simply being collocated (copresent) to being richly engaged in the organic environment. Telepresence robots are mobile robot units that can be moved and controlled by a remote person (e.g., homebound child) in a local environment (e.g., realworld classroom). These robots provide real-time audio and video exchange, with the person's face typically shown on the robot's "head" via face screen. The remote user is in control of the movement and behavior of the robot in the local environment. This control provides the remote user a degree of embodiment in the robot and the opportunity to be present and engage in the local environment.

Currently available telepresence robots differ from each other in significant ways. They have different mobility features; they may or may not allow pan and tilt of the camera; they have different microphone and speaker placements; and they have different network security features, among other things. Table 1 provides images and an overview of design features for the VGo and the Double2 robots used in this study.

\section{Background on Robotic Telepresence in Other Settings Robots for Adults}

Much work has been done on evaluating the use of telepresence robots by adults in offices (Desai et al., 2011; Johnson et al., 2015; Kristoffersson et al., 2013; Lee \& Takayama, 2011; Takayama \& Go, 2012; Tsui et al., 2011), health care (In Touch Technologies, 2003; Kristoffersson et al., 2013; Tsui \& Yanco, 2007), conferences (Neustaedter et al., 2016; Rae \& Neustaedter, 2017), and aging in place (Broekens et al., 2009; Kristoffersson et al., 2013; Lee \& Takayama, 2011; Sabelli et al., 2011; Tsai et al., 2007; Tsui et al., 2011), but very little research has been done on evaluating the use of this technology by homebound children to attend traditional schools.

\section{Robots for Children in Hospital or Homebound Settings}

The earliest attempt to use robots for virtually including children in traditional schools is a study of a movable telepresence robot called PEBBLES (Providing Education by Bringing Learning Environments to Students) (Yeung \& Fels, 2005). PEBBLES combined videoconferencing with simple robotics to provide hospitalbound children with a robot-mediated presence in their classroom. However, a significant difference between the PEBBLES robot and

Table 1

Double and VGo Robots

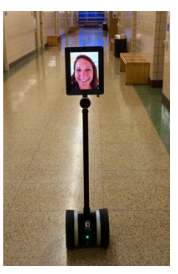

Double

$8-10 \mathrm{hr}$

Battery life

Camera pan (left and right)

Camera tilt (up and down)

Cliff sensors

Drive

Face screen, display static image

Face screen, life-size

Microphones

Navigation control

Number of cameras

Resolution of cameras

Speakers

Top speed

Two-way audio and video

Unit cost

Video encryption

Weight

Wheels are American Disabilities Act (ADA) Compliant

Wi-Fi access point switching
No

No

No

One large cylindrical wheel

Yes

9.7-inch LED, yes

One forward facing below screen

Mouse, arrow keys, joystick

One front facing and one always-on floor view

5 megapixels

One below face

$1.6 \mathrm{mph}$

Yes

$\$ 3000+$ cost of iPad

128-bit AES, HMAC-SHA1

$15 \mathrm{lbs}$

Yes

Yes

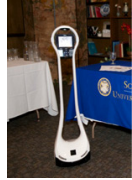

VGo
6- or 12-hr option

No

Yes, $180^{\circ}$

Yes

Two wheels and two casters

Yes

6-inch LCD, no

Four around video screen (two front and two back)

Mouse, arrow keys

One front facing

3 megapixels

One woofer in base and one tweeter in head

$2.75 \mathrm{mph}$

Yes

$\$ 5000$

SSL

$18 \mathrm{lbs}$

Yes

Yes 
current telepresence robots is that the PEBBLES robot system was movable but not mobile (i.e., no remote-controlled mobility) and needed assistance when moving from one class to another. Children using the PEBBLES robot did not have control over their mobility and thus may have incurred implicit social debt to their peers. Implicit social debt is the user's feeling that they are implicitly incurring a social debt to local users (e.g., classmates) who need to assist them. The burden of social debt has also been covered in the literature for adult users of telepresence technologies (e.g., with wearable and movable free-standing devices) by Rae et al. (2015) and in schools (Ahumada-Newhart \& Olson, 2019). Both of the telepresence robots used in this study, the VGo and the Double, include remote-controlled mobility that facilitates social interactions with peers.

\section{Robot Mobility}

The movable versus mobile aspects of telepresence robots highlight a significant difference in the technology. A significant difference in the population is that children who used the PEBBLES robot were hospital bound (i.e., in the hospital for long periods of time) and children in this study were homebound (i.e., restricted to the home environment for long periods of time). The hospital-bound children in the PEBBLES study had adults present in the hospital who could assist them when operating the robot. The children in this study were homebound and expected to operate the robots independently (even at very young ages, e.g., kindergarten). For the homebound population, adults may be home (depending on the age of the child) but may not necessarily be able to assist the child in using the robot to attend school. These differences in technology and user experience are significant to feelings of autonomy for the child operator. Being able to control the movement of the robot throughout the school and independently operate the technology allows for increased control over robot-mediated social experiences in school. The increased autonomy and level of participation afforded by mobile telepresence robots may allow for increased engagement over being connected via a static method such as video conferencing or nonmobile robotic device.

\section{What is Not Known}

Earlier work has outlined robot design feature recommendations for robot-mediated school attendance (Ahumada-Newhart \& Olson, 2019), child experiences with using a robot to attend school (Newhart et al., 2016, 2017), and challenges educators face with robot use in traditional schools (Newhart \& Olson, 2017). However, to date, there has not been a consistent framework for evaluating robot-mediated levels of presence and engagement of virtually included children in traditional classrooms. How might robotic avatars be used to provide meaningful social and developmental experiences for homebound children? It is not known how robotmediated levels of presence and engagement can be consistently evaluated in classroom, community, extracurricular, or other social activities. Improved understanding of the interplay between embodied robots and developmental social processes will contribute to future research in evaluating robot-mediated child development experiences. This paper extends relevant theories to create a framework that is informed by empirical data. This framework may facilitate growing knowledge to fill the gap between what is known about telepresence robots in corporate/work settings and what is known about telepresence robots in learning environments. This knowledge may help create improved technologies and social practices for equitable robot-mediated social and developmental experiences.

\section{Study Approach}

Empirical data for this paper collected via holistic case studies in a multicase, qualitative exploratory study. Qualitative case study methodology allows for the study of complex phenomena within their contexts as well as holistic evaluation of novel practices. The purpose of this paper is to provide a framework, informed by empirical data and supported by relevant theories, for examining the robot-mediated presence of homebound children. In addition to empirical data, the resulting framework is supported by three relevant theories. In his bioecological systems theory, Bronfenbrenner (2005) stressed the importance of the environmental supports necessary for healthy human development. This theory supports the importance of maintaining social connectedness for this population via robotic telepresence. In their self-determination theory, Ryan and Deci (2000) explored how unique features of telepresence robots facilitate meeting basic human needs for the homebound child. Presence theory (Biocca et al., 2003) explains why robotic telepresence may provide a unique avenue for achieving both a physical and a psychological sense of presence via these technologies.

\section{Relevant Developmental Theories}

\section{Bioecological Systems Theory}

Schools are places where children learn academic, emotional, and social lessons, all of which are intertwined. Many children experience loneliness and depression when homebound (Bennett, 1994; Weitzman, 1986). Earlier work on telepresence robots was centered on what children needed from the design of robots to facilitate social experiences (Ahumada-Newhart \& Olson, 2019). In this study, to explore robot-mediated developmental experiences of homebound children, Bronfenbrenner's bioecological framework for human development provides a foundation for highlighting the importance of remaining socially connected to peers, school, and community (Bronfenbrenner, 2005). Bronfenbrenner (2005) formulated his bioecological systems theory to explain how the inherent qualities of children and their environments interact to influence how they grow and develop. Bronfenbrenner's theory emphasizes the importance of studying children in multiple environments, also known as ecological systems, in the attempt to understand their development.

According to this theory, children typically find themselves enmeshed in various ecosystems, from the most intimate home ecological system to the larger school system, and then to the more expansive systems that include society, culture, and government/ social policy. Each of these ecological systems inevitably interacts with and influences each other in all aspects of the children's lives. Bronfenbrenner proposed that the microsystem is the smallest and most immediate environment in which children live. As such, the microsystem comprises the daily home, school or daycare, peer group, and community environment of the children. 
Interactions within the microsystem typically involve personal relationships with family members, classmates, teachers, and caregivers. How these groups or individuals interact with the children will affect how they grow. But what happens when a child is homebound and these environmental supports, critical components of the microsystem, are removed? Can robot-mediated interactions reestablish these crucial environmental supports of the microsystem?

The homebound child is restricted to the physical environments of home and hospital for social experiences. Very little is known about the long-term effects of this disruption to a child's social environment as there has not been an alternative to the current homebound experience. A 2009 study of childhood cancer survivors identified negative long-term social outcomes such as poor educational attainment, less than optimal employment status, and interpersonal relationship issues for this population (Gurney et al., 2009). Gurney et al. (2009) also highlighted the need for future studies to incorporate existing knowledge on risk profiles directly into clinical management and into social settings, such as school, to design interventions that may improve these outcomes.

To illustrate what has traditionally taken place, Figure 1 represents a simplified view of the environmental supports in a traditional childhood microsystem. This microsystem of support is radically altered when a child becomes homebound. Figure 2 demonstrates a simplified view of the homebound experience: peers, school, and community are removed, and health care is introduced as a new environment in the child's microsystem. The homebound child is restricted to the physical environments of home and hospital for social experiences. All participants in this study reported the addition of regular interactions with a healthcare team and almost complete removal of their school, community, and peer activities when receiving homebound services without a robot. Very little is known about the long-term effects of this disruption to a child's social environment as there has not been an alternative to this traditional homebound experience. Recently, the use of telepresence robots provides a way to remain virtually connected to these supports throughout the homebound experience. Figure 3 illustrates the return of these supports, represented with the Wi-Fi symbol in the background, to signify that these supports are now experienced via digital means (i.e., robotic telepresence, Wi-Fi connectivity, and home device).

In this study, homebound children reported regaining the following environments via robot (Table 2): all participants reported the return of their school environment for classroom activities; three participants reported the return of community environment activities (i.e., church, boy scouts, field trips); and one participant reported a new environment, attending a ball game with peers (a mobile hotspot was used for connectivity).

\section{Self-Determination Theory}

In their SDT, Ryan and Deci posit that all humans have universal, innate psychological needs (i.e., competence, autonomy, and relatedness) and that people function and grow optimally only when these needs are met (Deci \& Ryan, 2002). As shown in Figure 4, the remote child on a robot can achieve competence in a number of ways: learning to drive the robot, academic learning in the classroom, and social learning with one's classmates. The remote child
Figure 1

Microsystem for Traditional Child

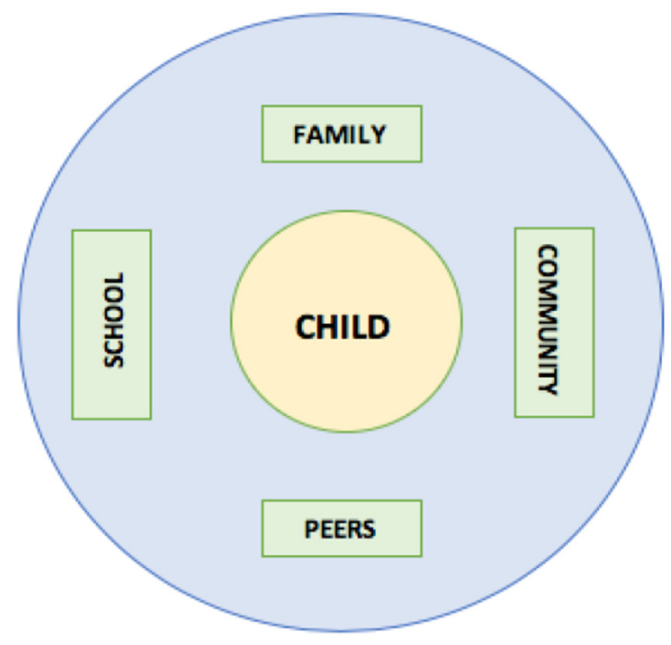

Figure 2

Microsystem for Homebound Child

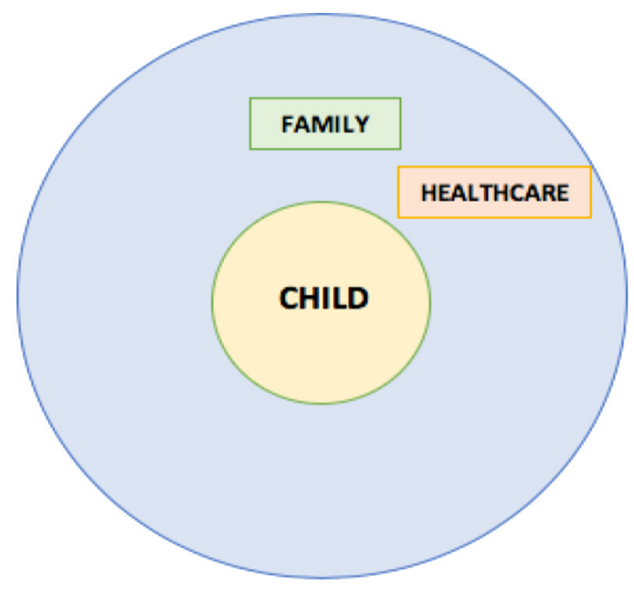

Figure 3

Robot-Mediated Microsystem

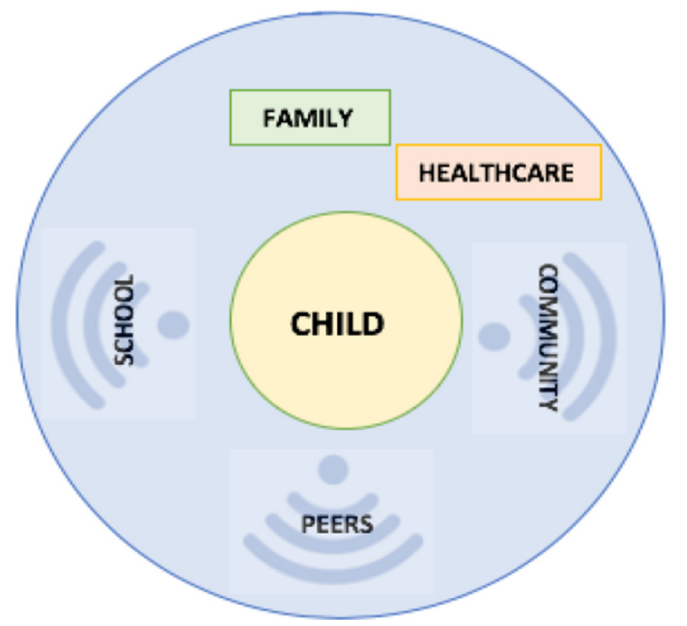


Table 2

Participant Reported Robot-Mediated Activities

\begin{tabular}{llllcc}
\hline & & & School & $\begin{array}{c}\text { Community } \\
\text { environment }\end{array}$ & $\begin{array}{c}\text { Peer } \\
\text { environment }\end{array}$ \\
\hline Case 1 & M & 2nd & $\times$ & $\times$ & \\
Case 2 & M & 5th & $\times$ & $\times$ & $\times$ \\
Case 3 & F & 11 th & $\times$ & $\times$ & \\
Case 4 & F & K & $\times$ & & \\
Case 5 & F & 8th & $\times$ & & \\
\hline
\end{tabular}

can achieve autonomy in a number of ways: logging in to the system and attending class on one's own, moving and zooming the camera to view objects and educational materials, and moving the robot around the classroom and school with similar accessibility as someone in a wheelchair. The remote child can also achieve relatedness through academic and social interactions with friends and teachers. Thus, a strong robot-mediated presence with high levels of engagement may allow a homebound child to meet these needs for optimal growth.

\section{Relevant Virtual Environment Theories}

\section{Presence Theory}

Many researchers have studied the concept of presence in virtual environments (Heeter, 2003; Nichols et al., 2000). These studies led to the emergence of presence as a theoretical response to the challenges that new media and virtual reality impose on communication scholars' understanding of how users process and experience media form and content (Biocca \& Delaney, 1995). These challenges arise from new media's immersive capacities, that is, their capability to make users believe that they are personally and physically "present" in the displayed environment. Steuer (1995) posited that presence is a state of consciousness, the (psychological)

\section{Figure 4}

Self-Determination Theory Applied to Robot-Mediated Environments

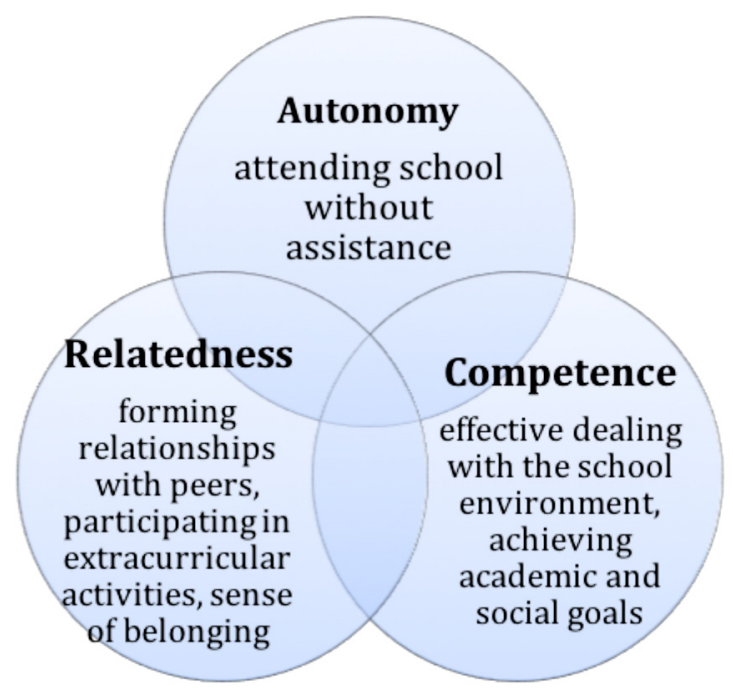

sense of being in an environment. Presence can be thought of as the experience of one's environment; it refers not just to one's surroundings as they exist in the physical world. Presence can refer to the perception of those surroundings as mediated by both automatic and controlled mental processes. This immersive capacity may be what allows virtual inclusion to have some degree of success for homebound children. Slater and Wilbur (1997) specified that the fundamental idea of being present in virtual environments is the experience of the virtual environment as the more engaging reality than the surrounding physical world. They further explained that people consider the environment specified on the remote users' screen as places visited rather than as images seen.

For this study, we explored presence in robot-mediated experiences. The concept of being present in virtual environments was extended to the concept of being present in robot-mediated organic (i.e., real-world) environments. In order for virtual inclusion to successfully allow children to interact with their school community, the remote child must consider their robot-mediated classroom interactions as real-life experiences rather than images seen. How does this happen?

Unlike the synthetic virtual environments studied by Slater and Wilbur (1997), the child operator of a telepresence robot experiences an organic real-world classroom environment that is visible to the child only via a computer screen. At the same time, the child (via the robot) is "present" in a real-world physical environment, not a synthetic virtual environment. A sense of presence in that "virtual" classroom environment is critical to the sense of virtual inclusion. In order for the child to feel included, the child must feel present and recall what is viewed on the computer screen as academic and social experiences, not as images seen. Wirth et al. (2007) and Biocca and Delaney (1995) classify presence in virtual environments into three types: (a) spatial presence, (b) selfreflective presence, and (c) social presence. Figure 5 outlines how these concepts of presence can be extended to hybrid environments and experiences (i.e., robot-mediated organic environments and experiences).

Spatial Presence. Allowing the child to pilot or navigate a physical presence in an educational environment is a significant component of being virtually included. Ideally, the child is not dependent on the assistance of others for mobility and is afforded a similar level of autonomy as other children in selecting whom to talk to, where to go, and how far they are from others in various situations (e.g., who they "sit" next to, whether they "sit" at the front or the back of the classroom). Mobile telepresence robots allow for spatial presence of the remote child in the classroom because the homebound child is physically represented in the classroom via the robot. Homebound children feel this presence in their ability to approach others, bump into things, and move toward/away from objects or people.

Self-Reflective Presence. In Biocca and Delaney's (1995) classification, self-reflective presence refers to the perception that the surrounding environment offers the same responses that one is accustomed to in a "real" environment. For homebound children, the desks, bulletin boards, whiteboards, and other components of a traditional classroom, that are observable on the remote child's computer display, offer the same responses they experienced as traditional students. The environment the remote child is viewing on screen is reflective of their world because it is, in fact, a real 
Figure 5

Virtual and Robot-Mediated Presence

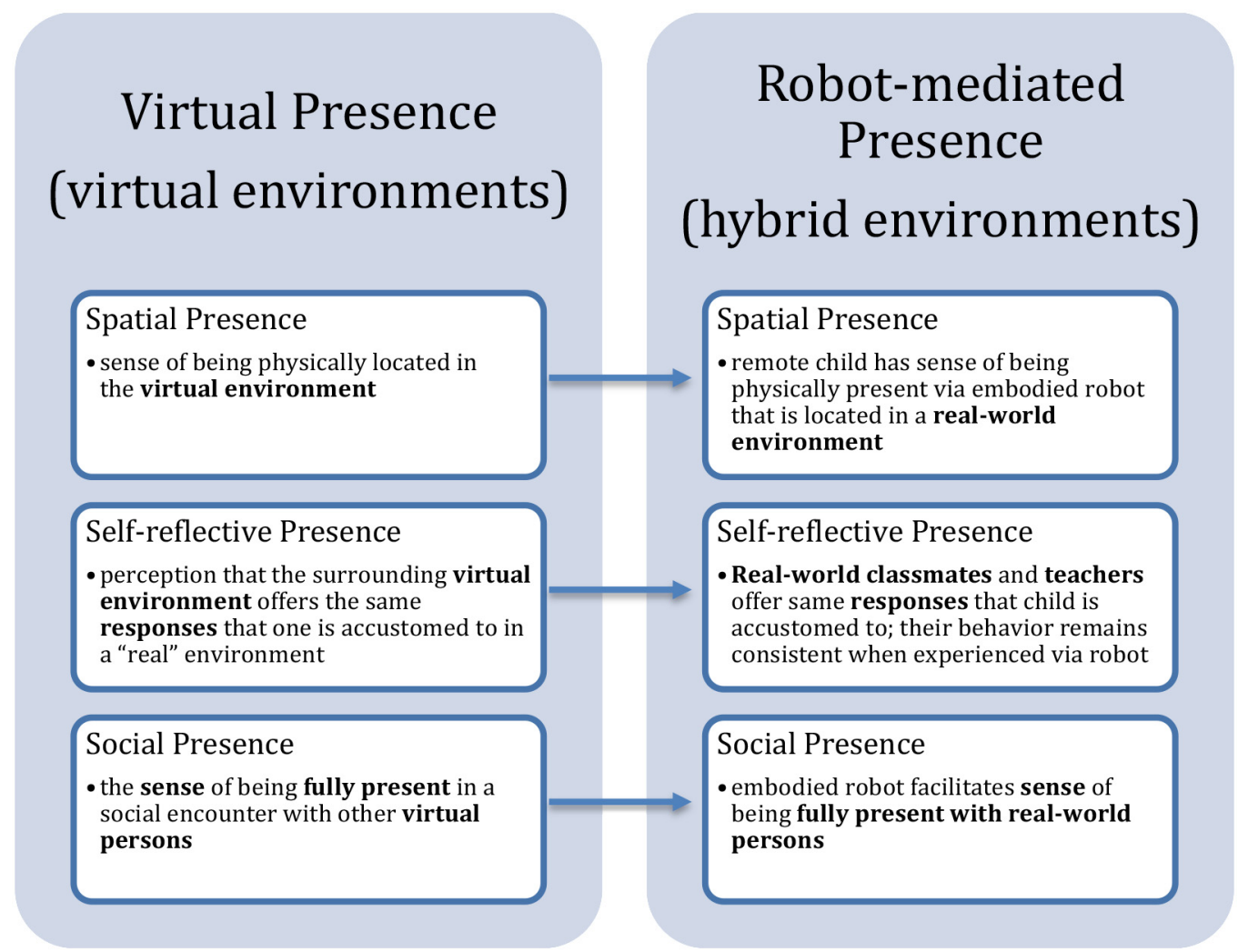

environment that reacts in a way to which they are accustomed (e.g., taking attendance, waiting in line, and raising a hand to speak).

Social Presence. The third pillar of presence, social presence, refers to the sense of being present in a social encounter with another person, for instance, via a Skype or conference call where two speakers are at different physical locations but can feel fully present with each other in the context of the conversation. Vrasidas and McIsaac (1999) define social presence as the degree to which a person feels "socially present" in a mediated situation, linking the issue to a larger social context including motivation, attitudes, social interaction, and social equality. For academic success and social emotional learning, the complexities of social presence and the role that telepresence robots play in restricting or enhancing social presence are particularly valuable to understand the development of improved systems of support and technology.

Homebound children use telepresence robots to participate in school experiences similar to those they participated in before being homebound. They transition from stationary lectures, to walking the halls, to attending assemblies, to "eating" in the cafeteria with friends, to going on field trips, and even to attending after school activities with peers-all via a remote-controlled robotic avatar. Robot-mediated accessibility to school activities may provide children with valuable developmental experiences. This paper explores the interplay between developmental theories and presence theories to support robot-mediated presence and engagement for optimal child development. The foundational framework that emerged from synthesis of relevant theories is seen in Table 3.

\section{Methodology}

This study is a multicase, qualitative, exploratory study that is aimed at growing knowledge on the robot-mediated presence of children in traditional schools. This study employs a case study research methodology. A case study is a research strategy and an empirical inquiry that investigates a phenomenon within its real-life context. More specifically, case study methodology allows for a holistic, in-depth investigation (Feagin et al., 1991), a description of "the real-life context in which the intervention has occurred," and a description of "the intervention itself ..." (Yin, 1994). To provide an in-depth, multidimensional study of real-world experiences of virtual inclusion via telepresence robots in the classroom, data were collected from multiple sources and sites to bring out the details from the viewpoints of the participants (Yin, 1994). This study explores the interconnectedness of all participants in robot-mediated school experiences that facilitate or challenge perceived presence in the classroom. Each case consists of a homebound child and their parents and classmates. Data for this study were collected during 2013-2017 and were analyzed as a subset of a larger, ongoing, national multicase study. 
Table 3

Theories That Support Levels of Robot-Mediated Engagement

\begin{tabular}{|c|c|c|c|}
\hline & Level 1 & Level 2 & Level 3 \\
\hline & $\begin{array}{l}\text { Copresent: minimal } \\
\text { interaction }\end{array}$ & $\begin{array}{l}\text { Cooperating: intermediate } \\
\text { interaction }\end{array}$ & $\begin{array}{l}\text { Collaborating: dynamic, } \\
\text { embodied interaction }\end{array}$ \\
\hline \multicolumn{4}{|c|}{ How do relevant theories extend into experiencing organic environments (i.e., real-world schools) via synthetic means (i.e., robotic telepresence)? } \\
\hline Social presence theory & Copresence: low level of presence & $\begin{array}{l}\text { Psychological involvement: } \\
\text { some feelings of presence }\end{array}$ & $\begin{array}{l}\text { Behavioral engagement: high level of } \\
\text { presence }\end{array}$ \\
\hline Bioecological systems theory & $\begin{array}{l}\text { Accessing school, peer, } \\
\text { and community environments }\end{array}$ & $\begin{array}{l}\text { Interacting with others in school, } \\
\text { peer, and community activities }\end{array}$ & $\begin{array}{l}\text { Forming friendships/bonds and actively } \\
\text { engaging with others in support } \\
\text { environments }\end{array}$ \\
\hline Self-determination theory & $\begin{array}{l}\text { Autonomy: attending } \\
\text { school without assistance }\end{array}$ & $\begin{array}{l}\text { Competence: effective dealing } \\
\text { with the environment, achieving } \\
\text { academic and social goals }\end{array}$ & $\begin{array}{l}\text { Relatedness: forming relationships with } \\
\text { peers, participating in extracurricular } \\
\text { activities, sense of belonging }\end{array}$ \\
\hline
\end{tabular}

\section{Research Design}

\section{Data Sources}

To increase trustworthiness in the data and confirm validity of the processes, Yin's (1994) recommendation to use multiple sources of data was followed. Triangulation, protocols that are used to ensure accuracy and alternative explanations (Stake, 1995), of the data was accomplished by collecting data from different sources (i.e., homebound children, their parents, and classmates), and using different methods (semistructured interviews, focus group interviews, and observations). For this paper, sources of data consist of semistructured interviews of homebound children and their parents, classroom observations while the robot was deployed, and focus group interviews of classmates who attended school with a peer who was using a robot. It was expected that the concepts and themes related to perceived robot-mediated presence of the homebound child would emerge from the multiple sources of data through inductive content analysis, open coding, and the constant comparative method recommended by Glaser and Strauss (1967). Semistructured interviews, classmate focus groups, and observation field notes were recorded, transcribed, and coded to identify patterns, similarities, and dissimilarities across all cases where each case represented one homebound child.

Observations took place in five different public school classrooms while a robot was deployed. Data collected on homebound child activities in the classroom were centered on robot-mediated activities and interactions. All classroom activities were represented in observation field notes. These observations lasted 45-60 min each.

Focus group interviews were conducted immediately after the observations in three classrooms. Focus group interviews were not possible after two of the classroom observations due to issues with district parental consent forms. Focus group discussions were limited to questions on the classmates' attitudes and perceptions of attending school with a robot in the classroom. Homebound children were present via robot and participated in the focus group discussions. Open responses were allowed for each question, with an average of 2-3 min allowed per response to each question. Focus group interviews lasted 5-10 min per school schedule restrictions.

Semistructured interviews were conducted with five homebound children and one parent for each case. Interview questions ranged from social experiences, academic learning, technology features, and perceived presence (feelings of autonomy, relatedness, and competence). For this paper, we coded sections of the interviews related to feeling present and engaged in school activities. Semistructured interviews lasted 20-50 min.

\section{Participants}

Focus group interviews were conducted with three full classrooms, totaling 65 children/adolescents $(n=65)$. Observations were conducted of 109 children/adolescents $(n=109)$ in five different classrooms while robots were deployed. Semistructured interviews were conducted with five homebound children and five parents $(n=10)$. In total, the participant sample size for this study was $(N=114)$, since all students who participated in the focus groups are also counted in the observations and interviews. The homebound child's gender, grade, approximate ages of classmates, model of robot used, and classroom sizes are presented in Table 4. Each homebound child represents one case, and all cases in this study were homebound as a secondary consequence of illness/ medical condition. Data were not collected on focus group participant

Table 4

Participants

\begin{tabular}{|c|c|c|c|c|c|c|c|}
\hline & Gender & Grade & $\begin{array}{l}\text { Duration of homebound } \\
\text { experience }\end{array}$ & $\begin{array}{l}\text { Approximate ages of } \\
\text { homebound child } \\
\text { and classmates }\end{array}$ & $\begin{array}{c}\text { Robot } \\
\text { used }\end{array}$ & $\begin{array}{l}\text { Class size } \\
\text { observed }\end{array}$ & $\begin{array}{c}\text { Focus group } \\
\text { participants }\end{array}$ \\
\hline Case 1 & M & 2nd & 14 months at time of interview, ongoing & $7-8$ years & VGo & 19 & 19 \\
\hline Case 2 & M & 5 th & 18 months at time of interview, ongoing & 10-11 years & VGo & 21 & 21 \\
\hline Case 3 & $\mathrm{~F}$ & 11th & 12 months at time of interview, ongoing & $16-17$ years & Double2 & 25 & 25 \\
\hline Case 4 & $\mathrm{~F}$ & $\mathrm{~K}$ & 8 months at time of interview, ongoing & $5-6$ years & Double2 & 24 & 0 \\
\hline Case 5 & $\mathrm{~F}$ & 8 th & 6 months & $13-14$ years & VGo & 20 & 0 \\
\hline
\end{tabular}


names, gender, or any other identifying information per school district guidelines.

Participant Recruitment and Informed Consent. All participants were provided with study information sheets approved by the university institutional review board and local school district. Study information sheets were read aloud by the interviewer before each focus group interview to provide ample time for questions about the study. Child participants received parental permission and gave verbal assent to being interviewed before focus group interviews were conducted.

\section{Analysis}

Miles and Huberman (1994) state that coding is analysis, while others (Basit, 2003) attest that coding and analysis are not synonymous. For this study, coding was viewed as a crucial aspect of analysis, and data were coded both during and after collection as an analytic tactic. Codes were developed as the data were coded and, as recommended by Hatch (2002), patterns were viewed not just as stable regularities but also as varying forms. Patterns and themes were characterized by similarity, frequency, and correspondence. The data also underwent several cycles of coding to generate relevant categories, concepts, and themes.

Initial coding was performed on transcripts and different parts of the data (i.e., text) following Glaser and Strauss's (1967) description of open coding where tentative labels are applied to sections of data and these labels are later classified under common concepts or categories as the data undergo multiple rounds of coding. A list of the code words for each transcript was compiled and compared across the individual cases. This allowed for checks to ensure that a code was used consistently throughout the transcripts. During these steps, notes were taken and recorded of emerging codes, the ideas they represented, and relationships between codes.

After the initial round of open coding, the research team discussed each coded section in terms of why it had been interpreted as meaningful and what it revealed about participant robot-mediated "presence" and "engagement." After discussion, the research team agreed upon a set of codes, each with a brief definition. These codes formed the initial analytic framework. The lead researcher then independently coded two each of the interviews, focus groups, and observations using the initial framework. Notes were taken on codes or impressions which did not fit the existing analytic framework. Codes were then refined, and new codes were introduced where necessary. The themes and concepts that emerged from the analysis were repeatedly compared with the transcripts to ensure their validity. The constant revision of the material allowed for some codes to be subsumed under broader and more abstract categories.

Using these codes, the research team evaluated the data for conceptual relatedness among the codes and formed categories. The process of refining, applying, and refining the analytical framework was repeated until no new codes were generated. The final framework consisted of 26 codes clustered into eight categories, each with a brief description of their meaning and examples of what elements might be summaries under that code. These code explanations provided consistency of coding for this study and lay the groundwork for incorporating future studies. Overall, two different analytic frameworks for evaluating perceived presence and engagement evolved: (a) a homebound child-centered analytic framework and (b) a classmate-centered analytic framework. Tables 5 and 6
Table 5

Codebook Sample: "Belonging” Category

\begin{tabular}{|c|c|}
\hline Codes & Description \\
\hline \multicolumn{2}{|r|}{ Belonging } \\
\hline Friendships & $\begin{array}{l}\text { Perception of friendships, reference to "friends," using } \\
\text { classmate names when describing positive experiences, } \\
\text { expressed concern for a member of the class }\end{array}$ \\
\hline Interactions & $\begin{array}{l}\text { Descriptions of robot-mediated activities with peers, re- } \\
\text { ports that include "then s/he said ..." reports of con- } \\
\text { versations overheard, descriptions of conversations } \\
\text { with peers }\end{array}$ \\
\hline Asking for help & $\begin{array}{l}\text { Instances of asking someone at school for help with the } \\
\text { robot, instances of asking anyone at school with } \\
\text { learning concepts }\end{array}$ \\
\hline Personalization & $\begin{array}{l}\text { Dressing the robot, asking friends to dress the robot, } \\
\text { taking/saving pictures of embodied robot with class- } \\
\text { mates/peers }\end{array}$ \\
\hline
\end{tabular}

provide two examples of categories from the final homebound child-centered analytic framework with sample codes and code descriptions.

\section{Results}

\section{Three Different Levels of Robot-Mediated Presence}

Synthesis of relevant theories and findings from empirical data informed three descriptive levels of presence in robot-mediated classroom experiences (Figure 6). These levels are on a scale (from copresent to collaborating) and, in this study, fluctuated according to tasks and settings. It is understood that all students may display varying levels of engagement based on tasks, content, classmates, and technical aspects of the robots. In this study, some participants displayed a high level of presence (i.e., collaborating) when participating in certain classes (e.g., science, second language), but displayed a low level of presence (i.e., copresent) when attending other classes (e.g., social studies, math). These fluctuations in robot-mediated presence are expected if they mimic the interests and behaviors of the child as if she or he were present in person.

However, varying levels of presence also occurred due to the technical aspects of the robots or home device. We found that some of these fluctuations in robot-mediated presence were disruptive to the learning experience and, at times, discouraged students.

Table 6

Codebook Sample: "Movement" Category

Codes Description

Movement (includes base mobility and turn of "head/camera")

No movement Neither the robot or other students moved in the classroom (e.g., got out of their seats or turned to look at something on a board; lecture-style seating, and lecture-style instruction)

Low-level Observed robot was not moved at all when other students movement did show movement

Mid-level Observed robot was moved less than other student movement movements

High-level Observed robot was moved equal to other student movement movements 
Figure 6

Levels of Robot-Mediated Presence

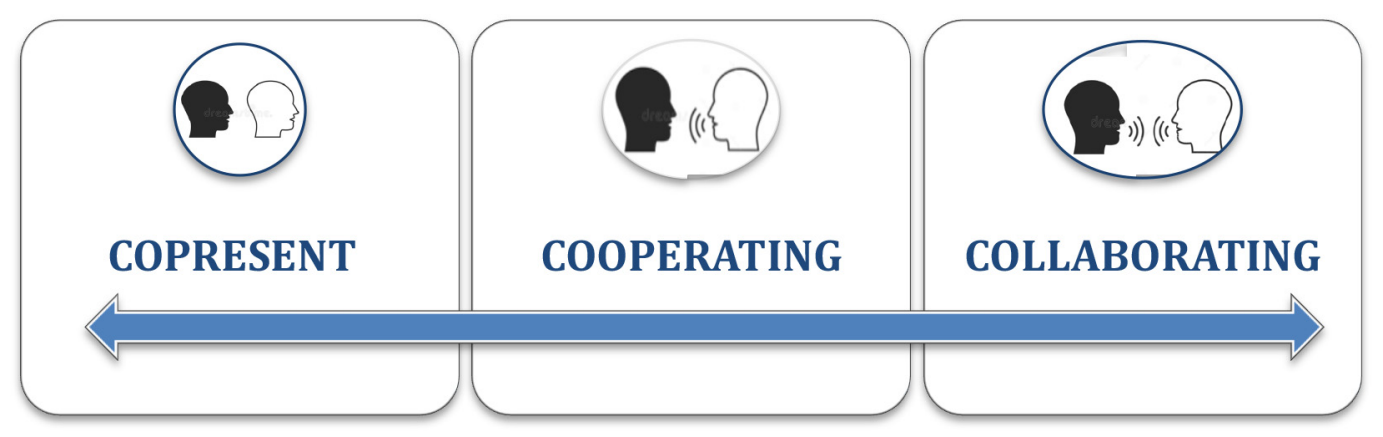

For example, a participant reported that they felt the robot was difficult to control and, consequently, did not move the robot at all when attending certain classes. Better understanding of how the robot-mediated behaviors and presence of children are displayed and perceived in the classroom will increase understanding of how future robots may be designed to better convey the presence, interests, and behaviors of the homebound child. This understanding will also contribute to improved social practices. The three levels of presence are described and then supported with participant data.

\section{Copresent}

Children who were copresent attended class but displayed minimal engagement unless directed by the teacher. In some classrooms, the remote children did not move the robot at all. Classmate groups approached the robot only when directed by the teacher. Some children reported that they rarely moved the robot because it was difficult to control or the room was too crowded. However, the children wanted to remain in attendance because they enjoyed hearing the class discussions to better understand the class material. The children knew the names of some classmates and classmates knew their names, but the remote children reported not knowing personal details about classmates.

\section{Cooperating}

Children who displayed cooperating behaviors occasionally moved their robots in the classroom when asked and knew some personal details about some of their classmates and shared some personal details (e.g., favorite sports team, foods). Some remote children provided and received encouragement from peers. Other children participated in groups with minimal direction from the teacher and moved their robots to join groups. Some children who displayed cooperating behaviors also actively texted/chatted with a peer during class if the robot lost connectivity or they had technical issues with the robot.

\section{Collaborating}

Children who displayed collaborating behaviors independently moved their robots in the classroom comparable to the amount of movement of their peers. Some participants attended school for 6 hours a day as well as extracurricular activities. Some children also reported having best friends in the classroom and one child was hugged by a classmate (the classmate hugged the embodied robot) when sharing good news.

The distinction between child-driven fluctuations in robot-mediated presence and technology-driven fluctuations in robot-mediated presence is central to this research. Through better understanding of child and robot behaviors in the classroom, scientists will be better able to evaluate the efficacy of this practice for homebound children. Future studies will explore if these identified levels of robot-mediated presence accurately reflect participant interests and behaviors and if the technology facilitates or disrupts existing participant interest in social and academic activities. Table 7 provides details on classes attended by each homebound participant, classes observed in this study, observed levels of robot-mediated presence, and reported feelings of robot-mediated presence.

\section{Framework for Evaluating the Robot-Mediated Presence of Children}

Data from study observations, semistructured interviews, and focus group interviews informed the descriptive levels of perceived presence and engagement. This study found that the social behaviors reported and observed in robot-mediated interactions emerged in patterns that supported these levels. For example, peer reports in focus group interviews emerged in patterns that supported these levels with comments such as "He doesn't move very much," "I'm glad he's back, I missed talking to him," and "She's always cracking jokes." Table 8 presents a theoretically supported framework for evaluating the robot-mediated presence of homebound children in schools. The descriptive levels of robot-mediated presence are informed by empirical data on observed behaviors and reported academic and social robot-mediated experiences.

\section{Discussion}

This framework is the first step toward a consistent measure for evaluating the robot-mediated presence and engagement of children and adolescents in schools as well as evaluating the quality of robotmediated social experiences. This study and framework provide foundational design implications for both social scientists and robot designers. Social and technical design implications are integral to any work seeking to explore this practice beyond basic use and collocation of robots in real-world settings. In other telepresence work with 
Table 7

Participant Levels of Robot-Mediated Presence

\begin{tabular}{|c|c|c|c|c|}
\hline & Class attended & Observed classes & Observed level of presence & Interview self-reported feelings of presence \\
\hline Case 1 & Full day & Math and reading & Collaborating: high-level of presence & $\begin{array}{l}\text { Felt extremely present in school, had close } \\
\text { friends, participated in most activities. }\end{array}$ \\
\hline Case 2 & Full day & Social Studies and Science & Collaborating: high-level of presence & $\begin{array}{l}\text { Felt extremely present in school, had close } \\
\text { friends, participated in most activities. }\end{array}$ \\
\hline Case 3 & English and Spanish & English & $\begin{array}{l}\text { Copresent: low-level of presence; } \\
\text { did not move the robot or speak }\end{array}$ & $\begin{array}{l}\text { Felt somewhat present in school, English } \\
\text { was favorite subject before homebound } \\
\text { but room layout made it difficult to } \\
\text { participate. Reported being more active } \\
\text { in Spanish class due to room layout. }\end{array}$ \\
\hline Case 4 & Full day & Reading & $\begin{array}{l}\text { Cooperating: moved when asked, } \\
\text { answered questions when asked }\end{array}$ & $\begin{array}{l}\text { Felt somewhat present in school. Knew a } \\
\text { little about classmates but moved only } \\
\text { when directed by the teacher. }\end{array}$ \\
\hline Case 5 & History and Science & Science & $\begin{array}{l}\text { Cooperating: moved when asked, } \\
\text { answered questions when asked }\end{array}$ & $\begin{array}{l}\text { Enjoyed school, was not able to fully par- } \\
\text { ticipate in experiments but felt included in } \\
\text { discussions and lectures. Reported being } \\
\text { more active in English class during } \\
\text { discussions and group work. }\end{array}$ \\
\hline
\end{tabular}

populations that may experience being homebound, researchers have formed knowledge on basic patterns for older adult users of telepresence/social robots (Boissy et al., 2007; Koceski \& Koceska, 2016; Reis et al., 2018; Tsai et al., 2007). This framework is a first step toward identifying and understanding the patterns of robot-mediated experiences for homebound children.

This study highlights the importance of robot-mediated social presence and engagement through child social interactions and behaviors in three levels: copresent, cooperating, and collaborating. Identifying these levels of interaction and how they present in a classroom setting will not only inform improved social practices for robot-mediated interactions but also inform robot design for improved experiences. By understanding the social requirements and expectations of robot-mediated child interactions, robot designers can improve robot design requirements for deployment in these settings.

Table 8

Framework for Evaluating Robot-Mediated Presence of Homebound Children

\begin{tabular}{|c|c|c|c|}
\hline & Level 1 & Level 2 & Level 3 \\
\hline & Copresent: minimal interaction & Cooperating: intermediate interaction & $\begin{array}{c}\text { Collaborating: dynamic, embodied } \\
\text { interaction }\end{array}$ \\
\hline \multicolumn{4}{|c|}{ How do relevant theories extend into experiencing organic environments (i.e., real-world schools) via synthetic means (i.e., robotic telepresence)? } \\
\hline $\begin{array}{l}\text { Social presence } \\
\text { theory }\end{array}$ & Copresence: low level of presence & $\begin{array}{l}\text { Psychological involvement: some } \\
\text { feelings of presence }\end{array}$ & $\begin{array}{l}\text { Behavioral engagement: high level of } \\
\text { presence }\end{array}$ \\
\hline $\begin{array}{l}\text { Bioecological systems } \\
\text { theory }\end{array}$ & $\begin{array}{l}\text { Accessing school, peer, and } \\
\text { community environments }\end{array}$ & $\begin{array}{l}\text { Interacting with others in school, peer, } \\
\text { and community activities }\end{array}$ & $\begin{array}{l}\text { Forming friendships/bonds and actively } \\
\text { engaging with others in support } \\
\text { environments }\end{array}$ \\
\hline \multirow[t]{2}{*}{$\begin{array}{l}\text { Self-determination } \\
\text { theory }\end{array}$} & $\begin{array}{l}\text { Autonomy: attending school } \\
\text { without assistance }\end{array}$ & $\begin{array}{l}\text { Competence: effective dealing with the } \\
\text { environment, achieving academic and } \\
\text { social goals }\end{array}$ & $\begin{array}{l}\text { Relatedness: forming relationships with } \\
\text { peers, participating in extracurricular } \\
\text { activities, sense of belonging }\end{array}$ \\
\hline & Copresent (low level of presence) & Cooperating (some feelings of presence) & Collaborating (high level of presence) \\
\hline \multicolumn{4}{|c|}{ What does this look like for robot-mediated experiences in the classroom? } \\
\hline Homebound child & $\begin{array}{l}\text { Attending class; knowing classmate } \\
\text { names; joining groups when } \\
\text { asked; minimal (if any) movement } \\
\text { of robot in class }\end{array}$ & $\begin{array}{l}\text { Greeting classmates; sharing personal } \\
\text { details (e.g., likes, dislikes); encour- } \\
\text { agement (e.g., cheering for class } \\
\text { teams); occasionally self-select groups; } \\
\text { occasionally move robot without being } \\
\text { asked; asking for help }\end{array}$ & $\begin{array}{l}\text { Self-selection of groups; initiating } \\
\text { conversations; joining extracurricular } \\
\text { clubs; eating lunch with friends; } \\
\text { attending community activities } \\
\text { (e.g., clubs, religious services); regular } \\
\text { movement in the classroom } \\
\text { comparable to traditional student }\end{array}$ \\
\hline Classmates & $\begin{array}{l}\text { Knowing remote student's name; } \\
\text { greeting remote student; including } \\
\text { remote student when asked }\end{array}$ & $\begin{array}{l}\text { Greeting remote student; asking remote } \\
\text { student personal questions; sharing } \\
\text { personal details with remote student; } \\
\text { encouraging remote student; occasion- } \\
\text { ally invite remote student to join group; } \\
\text { assisting robot when asked }\end{array}$ & $\begin{array}{l}\text { Including remote student in groups; } \\
\text { initiating conversations with remote } \\
\text { student; eating lunch with remote } \\
\text { student; assisting the robot when not } \\
\text { asked; moving out of the robot's way } \\
\text { when it is moving }\end{array}$ \\
\hline
\end{tabular}


Findings from this study will contribute to research in different fields as most human-computer and human-robot interactions are complex and interdisciplinary. Future research by social scientists may build and refine the framework to better capture robot-mediated learning experiences that contribute to higher levels of presence and engagement for homebound children in traditional schools. In addition, robot designers can build on this work for improved robot features that facilitate presence and engagement for homebound children. Contributions through this work may extend beyond homebound child populations to other populations who experience being homebound due to other barriers (e.g., medical, geographic, and political) in all stages of human development.

\section{Limitations}

Limitations of this study include the relatively small sample size. Studying robots in real-world settings is extremely difficult and time-consuming. However, findings from this study contribute a strong first step toward consistency in evaluating robot-mediated experiences in learning environments.

\section{Conclusion}

This work makes a strong contribution to the field through a framework that is informed by empirical data and theoretically supported to evaluate the robot-mediated presence of children. This framework provides the first step toward consistent evaluation of robot-mediated presence and engagement for the homebound population. Understanding the social contexts and developmental needs of homebound children and how they can be achieved via robotic avatars will aid in developing more effective support and technological systems. As autonomous and semiautonomous features are improved and added to robotic telepresence systems, this framework will continue to aid future research in evaluating the efficacy of technological features and social practices that contribute to optimal robot-mediated learning and development.

\section{References}

Ahumada-Newhart, V., \& Olson, J. S. (2019). Going to school on a robot: Robot and user interface design features that matter. ACM Transactions on Computer-Human Interaction (TOCHI), 26(4), 1-28. https://doi.org/10.1145/ 3325210

Basit, T. (2003). Manual or electronic? The role of coding in qualitative data analysis. Educational Research, 45(2), 143-154. https://doi.org/10.1080/ 0013188032000133548

Bennett, D. S. (1994). Depression among children with chronic medical problems: A meta-analysis. Journal of Pediatric Psychology, 19(2), 149-169. https://doi.org/10.1093/jpepsy/19.2.149

Biocca, F., \& Delaney, B. (1995). Immersive virtual reality technology. In F. Biocca \& M. R. Levy (Eds.), Communication in the age of virtual reality (pp. 57-124). Lawrence Erlbaum Associates.

Biocca, F., Harms, C., \& Burgoon, J. K. (2003). Toward a more robust theory and measure of social presence: Review and suggested criteria. Presence (Cambridge, Mass.), 12(5), 456-480. https://doi.org/10.1162/ 105474603322761270

Boissy, P., Corriveau, H., Michaud, F., Labonté, D., \& Royer, M.-P. (2007). A qualitative study of in-home robotic telepresence for home care of community-living elderly subjects. Journal of Telemedicine and Telecare, 13(2), 79-84. https://doi.org/10.1258/135763307780096195
Broekens, J. M., Heerink, M., \& Rosendal, H. (2009). Assistive social robots in elderly care: A review. Gerontechnology, 8(2), 94-103. https://doi.org/ 10.4017/gt.2009.08.02.002.00

Bronfenbrenner, U. (2005). Making human beings human: Bioecological perspectives on human development. SAGE.

Charlton, A., Pearson, D., \& Morris-Jones, P. H. (1986). Children's return to school after treatment for solid tumours. Social Science \& Medicine, 22(12), 1337-1346. https://doi.org/10.1016/0277-9536(86)90097-3

Desai, M., Tsui, K. M., Yanco, H. A., \& Uhlik, C. (2011). Essential features of telepresence robots. In Proceedings of the 2011 IEEE Conference on Technologies for Practical Robot Applications (TePRA) (pp. 15-20). IEEE. https://doi.org/10.1109/TEPRA.2011.5753474

Deci, E. L., \& Ryan, R. M. (2002). Overview of self-determination theory: An organismic dialectical perspective. In E. L. Deci \& R. M. Ryan (Eds.), Handbook of self-determination research (pp. 3-33). University of Rochester Press.

Disability Rights California. (2012). Special education rights and responsibilities: Information on the rights of students with significant health conditions. https://serr.disabilityrightsca.org.

Feagin, J. R., Orum, A. M., \& Sjoberg, G. (1991). The nature of the case study. In J. R. Feagin, A. M. Orum, \& G. Sjoberg (Eds.), A case for the case study. UNC Press Books.

Glaser, B. G., \& Strauss, A. L. (1967). The discovery of grounded theory. Weidenfield \& Nicholson.

Gurney, J. G., Krull, K. R., Kadan-Lottick, N., Nicholson, H. S., Nathan, P. C., Zebrack, B., Tersak, J. M., \& Ness, K. K. (2009). Social outcomes in the childhood cancer survivor study cohort. Journal of Clinical Oncology, 27(14), 2390-2395. https://doi.org/10.1200/JCO.2008.21.1458

Hatch, J. A. (2002). Doing qualitative research in education settings. SUNY Press.

Heeter, C. (2003). Reflections on real presence by a virtual person. Presence (Cambridge, Mass.), 12(4), 335-345. https://doi.org/10.1162/ 105474603322391587

In Touch Technologies. (2003). InTouch Health and Rehabilitation Institute at Santa Barbara collaborate to evaluate world's first mobile remote presence robot for healthcare [Press release]. http://www.intouchhealth .com/pr1-15-03.html

Johnson, S., Rae, I., Mutlu, B., \& Takayama, L. (2015). Can you see me now? How field of view affects collaboration in robotic telepresence. In Proceedings of the 33rd Annual ACM Conference on Human Factors in Computing Systems (pp. 2397-2406). ACM.

Kim, T., \& Biocca, F. (1997). Telepresence via television: Two dimensions of telepresence may have different connections to memory and persuasion. Journal of Computer-Mediated Communication, 3(2), Article JCMC325. https://doi.org/10.1111/j.1083-6101.1997.tb00073.x

Koceski, S., \& Koceska, N. (2016). Evaluation of an assistive telepresence robot for elderly healthcare. Journal of Medical Systems, 40(5), Article 121. https://doi.org/10.1007/s10916-016-0481-x

Kristoffersson, A., Coradeschi, S., \& Loutfi, A. (2013). A review of mobile robotic telepresence. Advances in Human-Computer Interaction, 1-17. Article 902316. https://doi.org/10.1155/2013/902316

Lee, M. K., \& Takayama, L. (2011). "Now, I have a body": Uses and social norms for mobile remote presence in the workplace. In Proceedings of the SIGCHI Conference on Human Factors in Computing Systems (pp. 33-42). ACM. https://doi.org/10.1145/1978942.1978950

Maslow, G. R., Haydon, A., McRee, A.-L., Ford, C. A., \& Halpern, C. T. (2011). Growing up with a chronic illness: Social success, educational/ vocational distress. Journal of Adolescent Health, 49(2), 206-212. https:// doi.org/10.1016/j.jadohealth.2010.12.001

Miles, M. B., \& Huberman, A. B. (1994). Qualitative analysis: An expanded sourcebook. SAGE.

Minsky, M. (1980, June). Telepresence. OMNI Magazine. New York, 45-51.

Nakanishi, H., Murakami, Y., \& Kato, K. (2009). Movable cameras enhance social telepresence in media spaces. In Proceedings of the 27 th International 
Conference on Human Factors in Computing Systems - CHI '09 (p. 433). ACM. https://doi.org/10.1145/1518701.1518771

Neustaedter, C., Venolia, G., Procyk, J., \& Hawkins, D. (2016). To beam or not to beam: A study of remote telepresence attendance at an academic conference. In Proceedings of the 19th ACM Conference on ComputerSupported Cooperative Work \& Social Computing (pp. 418-431). ACM.

Newhart, V. A., \& Olson, J. S. (2017). My student is a robot: How schools manage telepresence experiences for students. In Proceedings of the 2017 CHI Conference on Human Factors in Computing Systems (pp. 342-347). ACM. https://doi.org/10.1145/3025453.3025809

Newhart, V. A., Warschauer, M., Olson, J. S., \& Eccles, J. S. (2017). Go home and get better: An exploration of inequitable educational services for homebound children [Paper presentation]. IDC 2017 Workshop on Equity and Inclusivity at the ACM SIGCHI Interaction Design and Children Conference. https://escholarship.org/uc/item/8js3h9zc

Newhart, V. A., Warschauer, M., \& Sender, L. S. (2016). Virtual inclusion via telepresence robots in the classroom: An exploratory case study. The International Journal of Technologies in Learning, 23(4), 9-25. https:// doi.org/10.18848/2327-0144/CGP/v23i04/9-25

NHIS. (2016). National health interview survey. https://www.cdc.gov/nchs/ nhis/SHS/tables.htm

Nichols, S., Haldane, C., \& Wilson, J. R. (2000). Measurement of presence and its consequences in virtual environments. International Journal of Human-Computer Studies, 52(3), 471-491. https://doi.org/10.1006/ijhc .1999 .0343

Rae, I., \& Neustaedter, C. (2017). Robotic telepresence at scale. In Proceedings of the 2017 CHI Conference on Human Factors in Computing Systems (pp. 313-324). ACM.

Rae, I., Venolia, G., Tang, J. C., \& Molnar, D. (2015). A framework for understanding and designing telepresence. In Proceedings of the 18th ACM Conference on Computer Supported Cooperative Work \& Social Computing - CSCW'15 (pp. 1552-1566). ACM. https://doi.org/10.1145/ 2675133.2675141

Reis, A., Xavier, R., Barroso, I., Monteiro, M. J., Paredes, H., \& Barroso, J. (2018). The usage of telepresence robots to support the elderly. In Proceedings of the 2nd International Conference on Technology and Innovation in Sports, Health and Wellbeing (pp. 1-6). IEEE.

Ryan, R. M., \& Deci, E. L. (2000). Self-determination theory and the facilitation of intrinsic motivation, social development, and well-being. American Psychologist, 55(1), 68-78. https://doi.org/10.1037/0003-066X .55 .1 .68

Sabelli, A., Kanda, T., \& Hagita, N. (2011). A conversational robot in an elderly care center: An ethnographic study. In Proceedings of the 6th International Conference on Human-Robot Interaction (pp. 37-44). Association for Computing Machinery.

Slater, M., \& Wilbur, U. K. S. (1997). A framework for immersive virtual environments (FIVE): Speculations on the role of presence in virtual environments. Presence (Cambridge, Mass.), 6(6), 603-616. https:// doi.org/10.1162/pres.1997.6.6.603
Stake, R. E. (1995). Qualitative research: Studying how things work. The Guilford Press.

Steuer, J. (1995). Defining virtual reality: Dimensions determining presence. In F. Biocca \& M. Levy (Eds.), Communication in the age of virtual reality (pp. 33-56). Lawrence Erlbaum Associates.

Sullivan, N. A., Fulmer, D. L., \& Zigmond, N. (2001). School: The normalizing factor for children with childhood leukemia: Perspectives of young survivors and their parents. Preventing School Failure, 46(1), 4-19. https://doi.org/10.1080/10459880109603338

Takayama, L., \& Go, J. (2012). Mixing metaphors in mobile remote presence. In Proceedings of the ACM 2012 Conference on Computer Supported Cooperative Work (pp. 495-504). ACM.

Tsai, T.-C., Hsu, Y.-L., Ma, A.-I., King, T., \& Wu, C.-H. (2007). Developing a telepresence robot for interpersonal communication with the elderly in a home environment. Telemedicine Journal and e-Health, 13(4), 407-424. https://doi.org/10.1089/tmj.2006.0068

Tsui, K. M., Desai, M., Yanco, H. A., \& Uhlik, C. (2011). Exploring use cases for telepresence robots. In Proceedings of the 6th International Conference on Human-Robot Interaction (pp. 11-18). ACM. https:// doi.org/10.1145/1957656.1957664

Tsui, K. M., \& Yanco, H. A. (2007). Assistive, rehabilitation, and surgical robots from the perspective of medical and healthcare professionals [Paper presentation]. AAAI Workshop on Human Implications of HumanRobot Interaction.

U.S. Census Bureau. (2016). 2016 QuickFacts on U.S. population. https:// www.census.gov/quickfacts/fact/table/US/PST045216

Vrasidas, C., \& McIsaac, M. S. (1999). Factors influencing interaction in an online course. American Journal of Distance Education, 13(3), 22-36. https://doi.org/10.1080/08923649909527033

Weitzman, M. (1986). School absence rates as outcome measures in studies of children with chronic illness. Journal of Chronic Diseases, 39(10), 799-808. https://doi.org/10.1016/0021-9681(86)90082-2

Wirth, W., Hartmann, T., Böcking, S., Vorderer, P., Klimmt, C., Schramm, H., Saari, T., Laarni, J., Ravaja, N., Gouveia, F. R., Biocca, F., Sacau, A., Jäncke, L., Baumgartner, T., \& Jäncke, P. (2007). A process model of the formation of spatial presence experiences. Media Psychology, 9(3), 493-525. https://doi.org/10.1080/15213260701283079

Yeung, J., \& Fels, D. I. (2005, May). A remote telepresence system for high school classrooms. In Proceedings of the Canadian Conference on Electrical and Computer Engineering (pp. 1465-1468). IEEE.

Yin, R. K. (1994). Case study research: Design and methods (2nd ed.). SAGE.

Received November 14, 2019

Revision received April 14, 2020

Accepted April 18, 2020 